\title{
Erratum to: High Prevalences and a Wide Genetic Diversity of Simian Retroviruses in Non-human Primate Bushmeat in Rural Areas of the Democratic Republic of Congo
}

Steve Ahuka-Mundeke, ${ }^{1,2,3}$ Ahidjo Ayouba, ${ }^{1}$ Placide Mbala-Kingebeni, ${ }^{2,3}$ Caroline Foncelle, ${ }^{1}$ Mukulumanya Mubonga, ${ }^{4}$ Simon-Pierre Ndimbo-Kumugo, ${ }^{2}$

Octavie Lunguya-Metila, ${ }^{2,3}$ Valentin Mbenzo-Abokome, ${ }^{5}$ Jean-Jacques Muyembe-Tamfum, ${ }^{2,3}$

Eric Delaporte, ${ }^{1}$ and Martine Peeters ${ }^{1}$

${ }^{1}$ UMI 233 TransVIHMI/INSERM1175, Institut de Recherche pour le Développement (IRD), University of Montpellier, 911 Avenue Agropolis, 34394 Montpellier, Cedex 1, France

${ }^{2}$ Institut National de Recherche Biomédicales, Kinshasa, Democratic Republic of Congo

${ }^{3}$ Service de Microbiologie, Cliniques Universitaires de Kinshasa, Kinshasa, Democratic Republic of Congo

${ }^{4}$ Institut Supérieur de Techniques Médicales de Walikale, Nord Kivu, Democratic Republic of Congo

${ }^{5}$ Projet Lac Tumba, WWF, Malebo, Democratic Republic of the Congo

ERratum to: EcoHealth

DOI: $10.1007 / \mathrm{s} 10393-016-1202-0$

The authors of this article should be listed as above.

The online version of the original article can be found under doi:10.1007/s10393-

016-1202-0.

Published online: March 3, 2017

Correspondence to: Martine Peeters, e-mail: martine.peeters@ird.fr 